\title{
Intelligent Transport Fleet Management System
}

\author{
Mehwish Iqbal, Shaista Noreen, Tayyaba Sabir, Salman Afghani \\ Electrical Engineering Department, APCOMS APCOMS, Khadim Hussain Road, Rawalpindi, Pakistan
}

\begin{abstract}
This paper discusses automation techniques that can be applied at bus centric level for removal of corruption. Through engineering techniques easy drive and friendly environment can be ensured. Controllers and sensors are used for automation. Our main idea is to develop a system for fair dealing and better management. It will also be locally maintainable. We are willing to design something which can halt the spurious activity and thus boost the economy in one of the many sectors of our country. We introduce a technology which will not only save money and time but also will prove to be beneficial and effective for the economy.
\end{abstract}

Keywords: Corruption, Automation, Controllers, Modules, Sensors

\section{Introduction}

Our project is aimed at developing sensors and controllers based solution for fleet management and monitoring for commercial use. Our aim is to minimize the problems and mismanagement in transport management and handling it electronically. The main idea is to develop a system for fair dealing and better management. It will also be locally maintainable. This is the spirit and main driving force behind this proposed system.

\section{Problems}

[1] The root problem of all our institutions is corruption population is the major concern in today's world, and hence an improvement in many sectors is of growing importance. Transport management is a huge issue in densely populated countries. The ways adopted by the commuters is certainly outdated. People involved in this business usually relay on extreme measures. It is crisis management rather than transport fleet management. Transportation business is extremely feasible but due to man practices problems in Pakistan the business is running in loss. Cities are not properly structured. As people, in developed countries live close to their work.

\section{Existing Solutions}

[2] MITSIMLab stands for simulation-based laboratory. It is developed for evaluating the impacts of alternative traffic management system designs at the operational level and assisting in subsequent design refinement.

\section{A Cellular Automation Traffic Flow Model For Online Simulation Of Traffic:}

[3] Information about traffic states in road networks is a basic requirement for the application of intelligent transport systems (ITS).It takes in to account the relationship between the quality and the vehicular densities.

\section{Dynamic Fleet Management For Cybercars:}

[4] Main problem in Intelligent Transportation System (ITS) is fleet management. For Cybercars, which are road vehicles with fully automated capabilities. A new transportation system called CTS (Cybernetic Transportation System) is made for passengers or goods. This Algorithm is based on Queuing thory which is specifically based on dynamic fleet management of cybercars, which can respond to random requests.

\section{Ewald Fleet Solution:}

\section{Practical Solutions}

[5] Maintenance and Repair Management

- Emergency Roadside Assistance

- Fuel Management

- Accident Management

- Motor Vehicle Records

- Nationwide Service 


\section{Vulocity Fleet Management Solutions:}

[6] Vulocity fleet management solution provides tracking/monitoring solutions. Due to its simplicity it is one of the most popular GPS devide among the fleet users. Vulocity Fleet management solutions have defined themselves by The 3 Eff's, which are Effortless, Effectiveness and Efficiency

- Effortless: Hardly takes any time to install and within no time the vehicle can be made ready with GPS tracking/monitoring

\section{- Effectiveness:}

Vulocity fleet management solution provides you with the minitrak where we can track information and make fast decisions

\section{- Efficiency:}

With GPS monitoring solution you can keep track of everything that your driver is doing. Chances of misuse of company vehicle can be reduced and soon employees will straighten their way as soon as they know that you are watching them.

\section{Architecture Of The System}

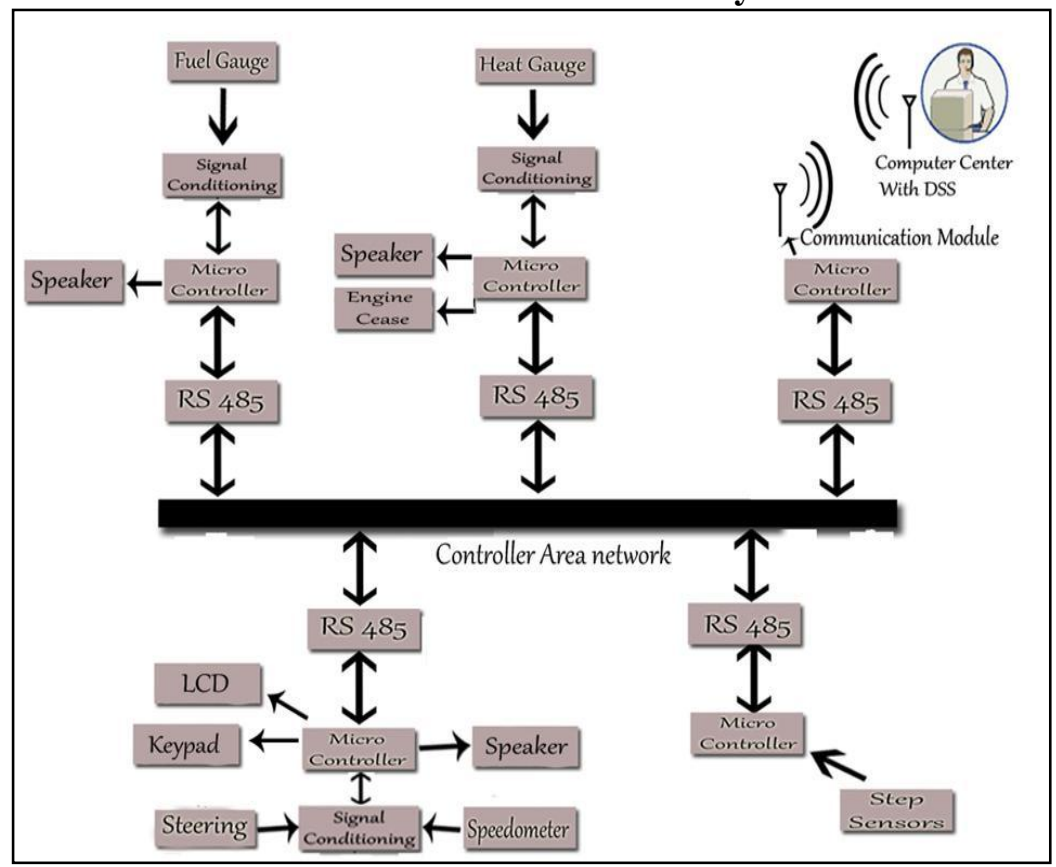

VI. Model Of Our Designed System

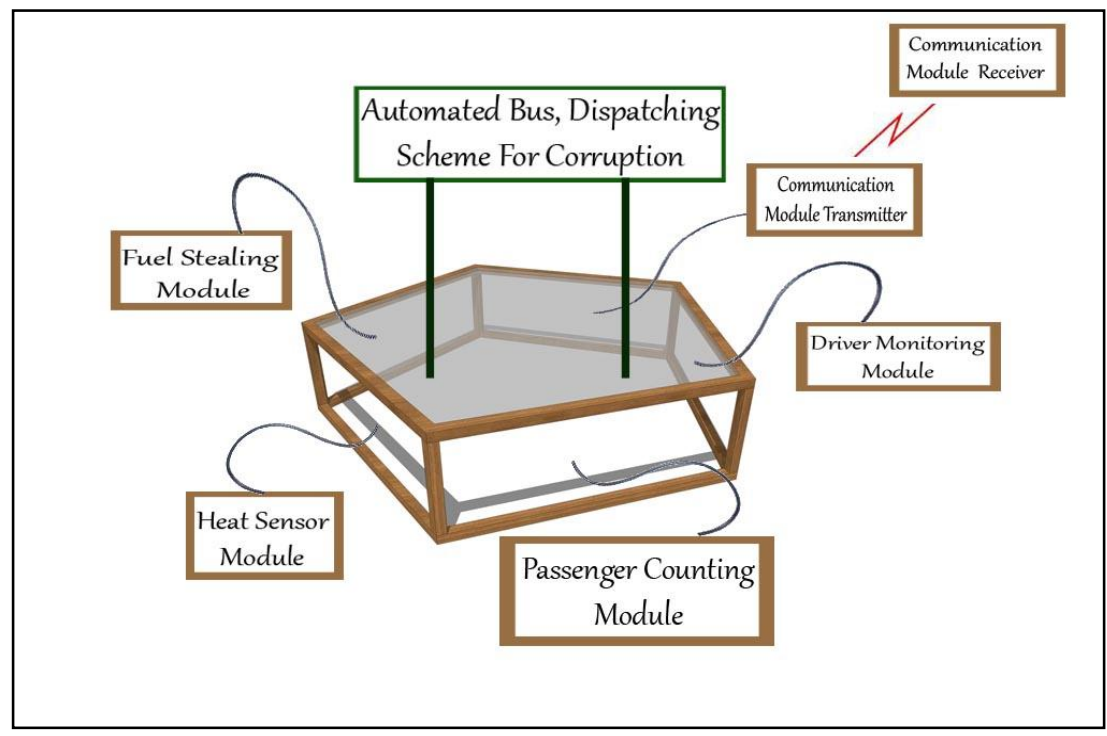




\section{Hardware Implemented}

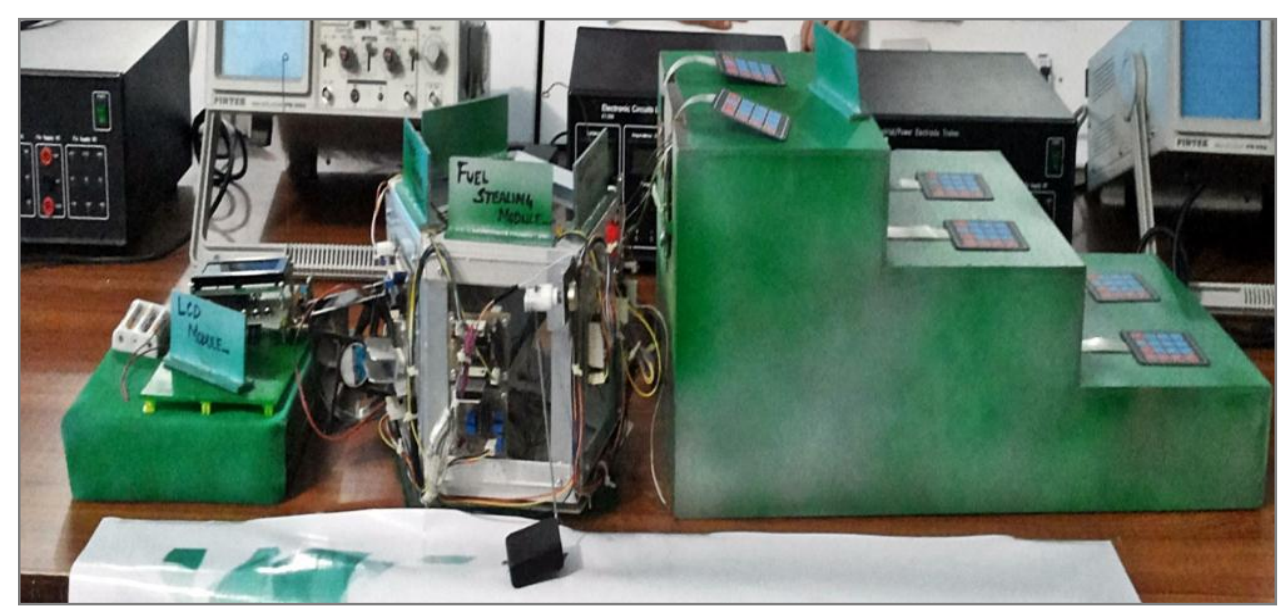

\section{Subsystems}

Our project consists of small and cost effective modules. The modules will be:

- Fuel Stealing detection Module.

- Passenger Counting Module.

- Driver Monitoring Module.

- Engine Condition Monitoring Module.

- Communication Module.

\section{Description Of Modules}

\section{Fuel Stealing Detection}

This is certainly the central and mandatory requirement. Our project will recognize fuel stealing. There will be 4 levels of fuel, those are full, quarter, half, (1/4)th level. These levels will be represented by potentiometer position and will be detected using a simple 4-level detector circuit and will be displayed on LCD screen via programming done on microcontroller. Three warnings will be given, after that engine will be seized.

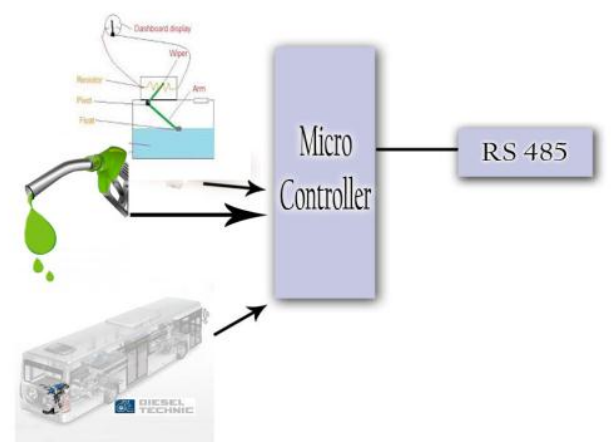

Figure 1: Fuel Stealing Module 


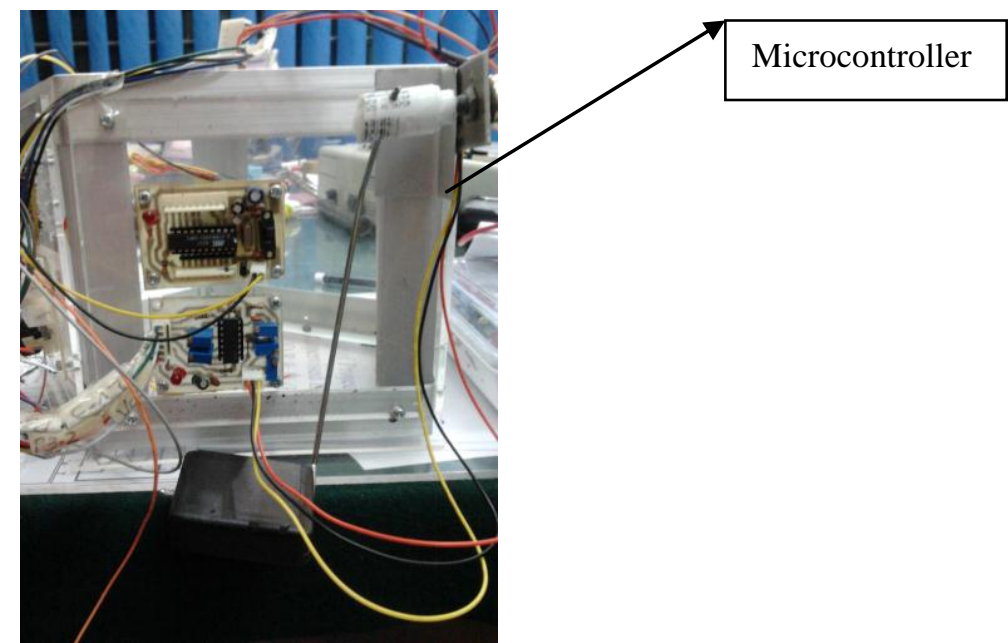

Figure 1-1 Implementation of fuel stealing module

\section{Passenger Counting}

This is another mandatory requirement. To detect ticketing, fraud passenger count must be taken by system. It is absolutely vital that it transmit an alert to the main panel so that the user is aware of the situation and is able to take necessary decision. It will be consisting of simple pull up resistors connected at each step. Whenever force will be applied logic 0 will be delivered and when the sequence will be a-b-c microcontroller will increment the register by 1 via assembly language. And when the sequence will be c-b-a, register will be decremented by 1 .No other pattern will be followed.

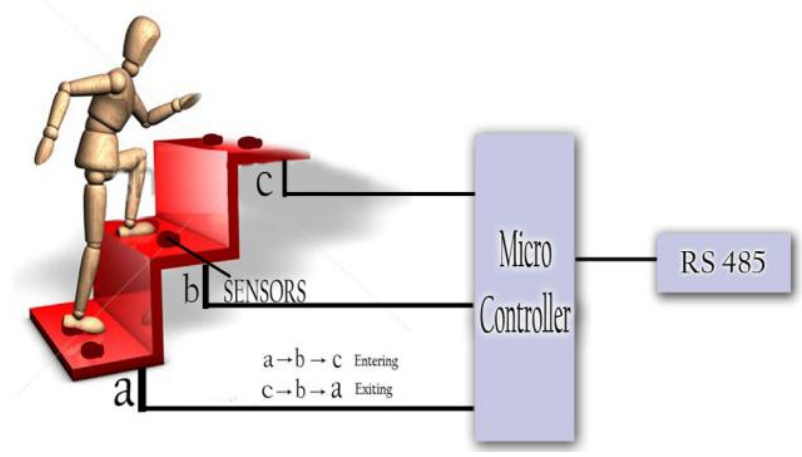

Figure 2: Passenger Counting Module

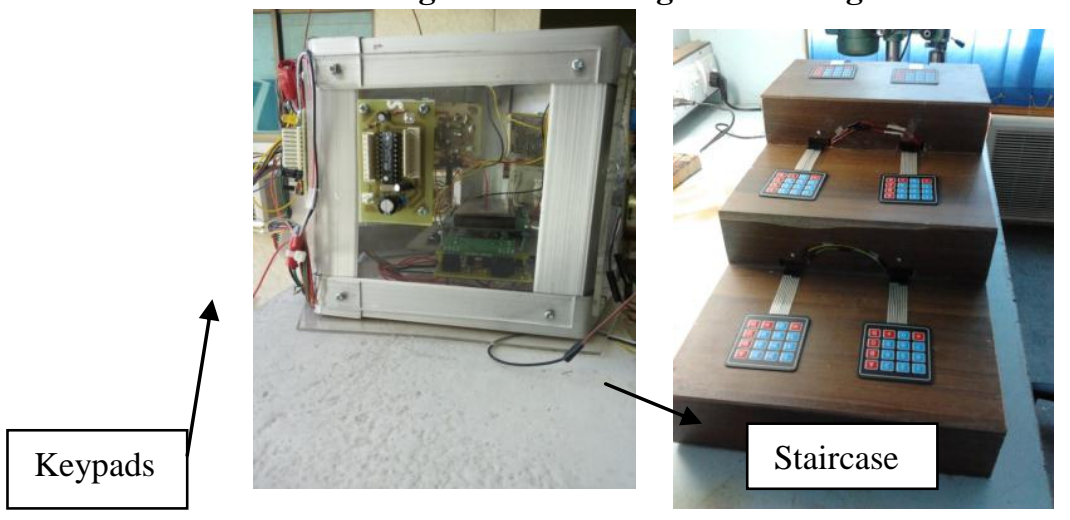

Figure 2-1 Implementation of Passenger counting module

\section{Driver Monitoring}

To detect rash driving, driving will be monitored by the system and if rash driving occurs then this system will communicate to the main module If the driver press the accelerator fastly and also turn the steering at a greater angle, it will be detected as rash driving It will be detected through IR detectors and specifications will be set using assembly language in 8051 microcontroller And will be displayed on 
LCD screen via programming done on microcontroller. Three warnings will be given, after that engine will be seized.

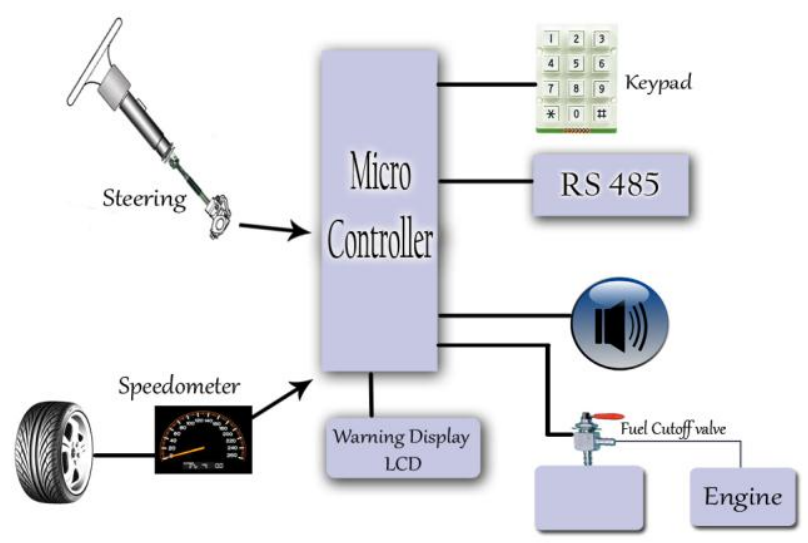

Figure 3: Driver Monitoring Module

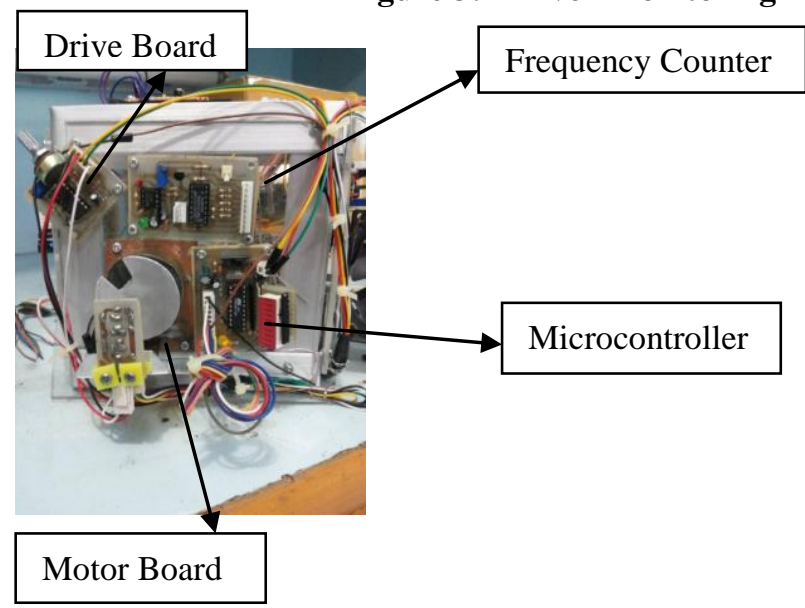

Figure 3-1 Implementation of Driver Monitoring Module

\section{Engine Condition Monitoring}

The system will monitor condition of an engine to avoid cease and to ensure timely service. If the engine condition is critical then this module will send data to main module so the user will take necessary decision about the maintenance of engine of that vehicle. Engine heat cycles will be monitored, if the heat cycles are large then it is an old engine, otherwise a new engine. We will also build a small engine using a high wattage resistor. Whenever heat is detected, fan will start.

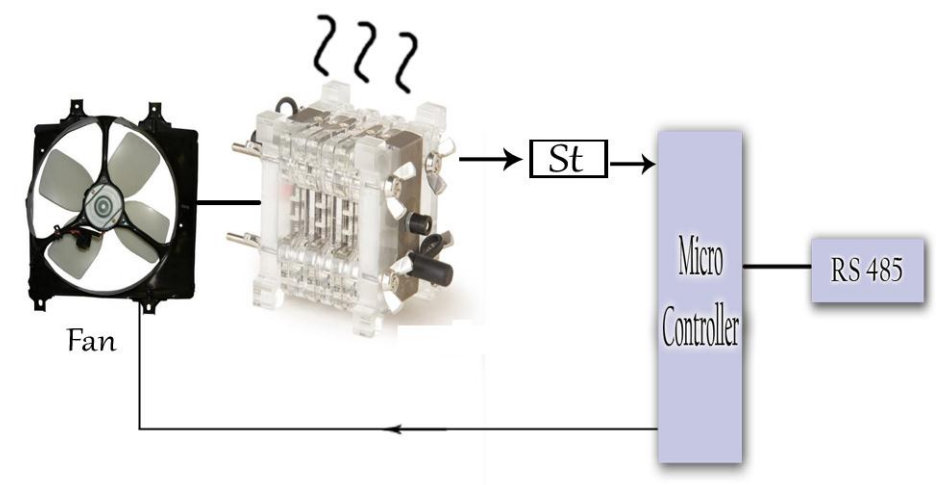

Figure 4: Engine Conditioning Module 


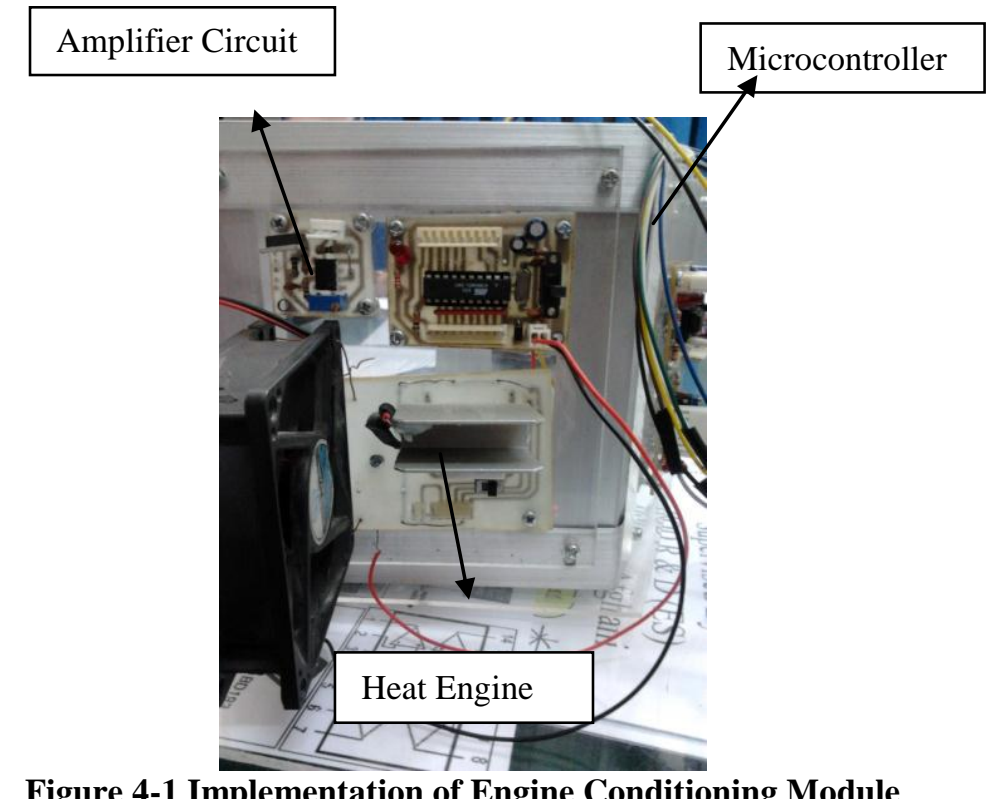

\section{Heat Cycles Of a Normal and Over-Heated Engine}

[7]As it is clear in the graph below that good engine graph has lesser dips. A bad engine graph has more dips.

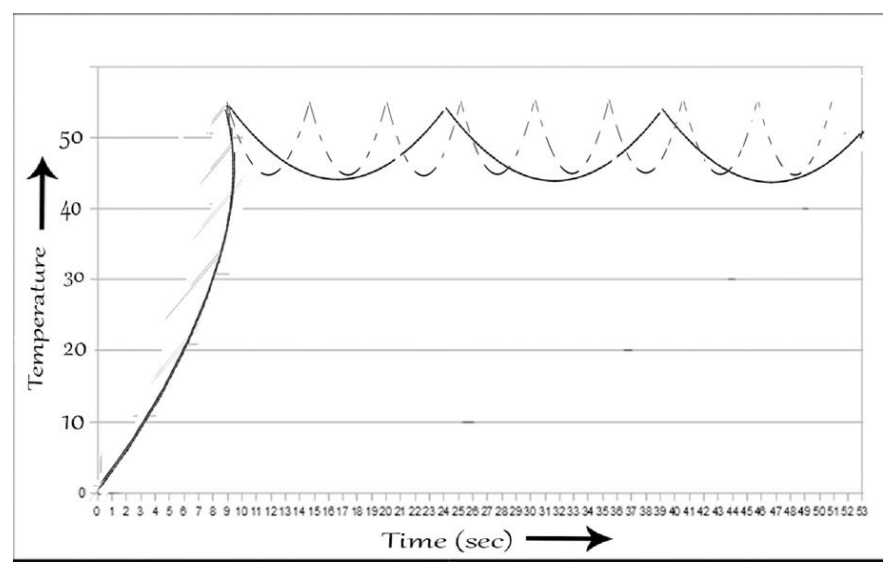

\section{Radio Data Transfer Module}

In this module all the information will be sent to the main panel and hence the owner can take action of every notice. As soon as the bus enters its coverage area, data will be automatically transferred from the communication module to the control room. Using serial ports of microcontroller (Tx and $\mathrm{Rx}$ ) and via networking this can be done. All the information will be sent from the antenna to the receiver side at the receiver side data will be displayed on LCD Screen. ${ }^{[8]}$ This is all done by networking, using RS 485 required action can then take place And hence everything can be taken under control via electronics.

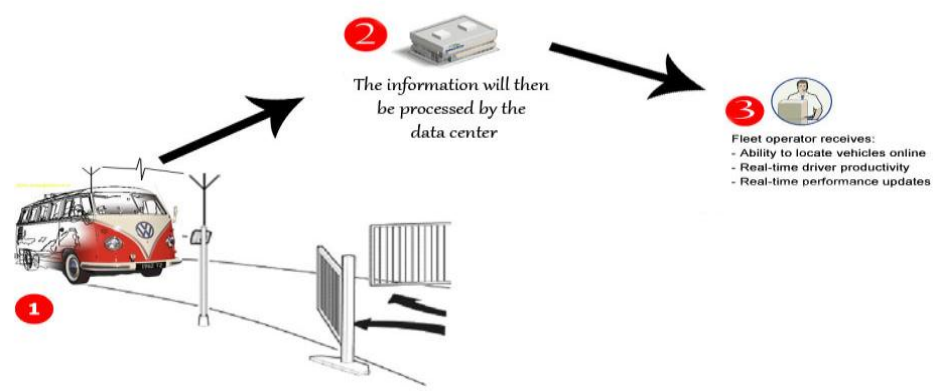

Figure 5: Communication Module 


\section{Transmitter}

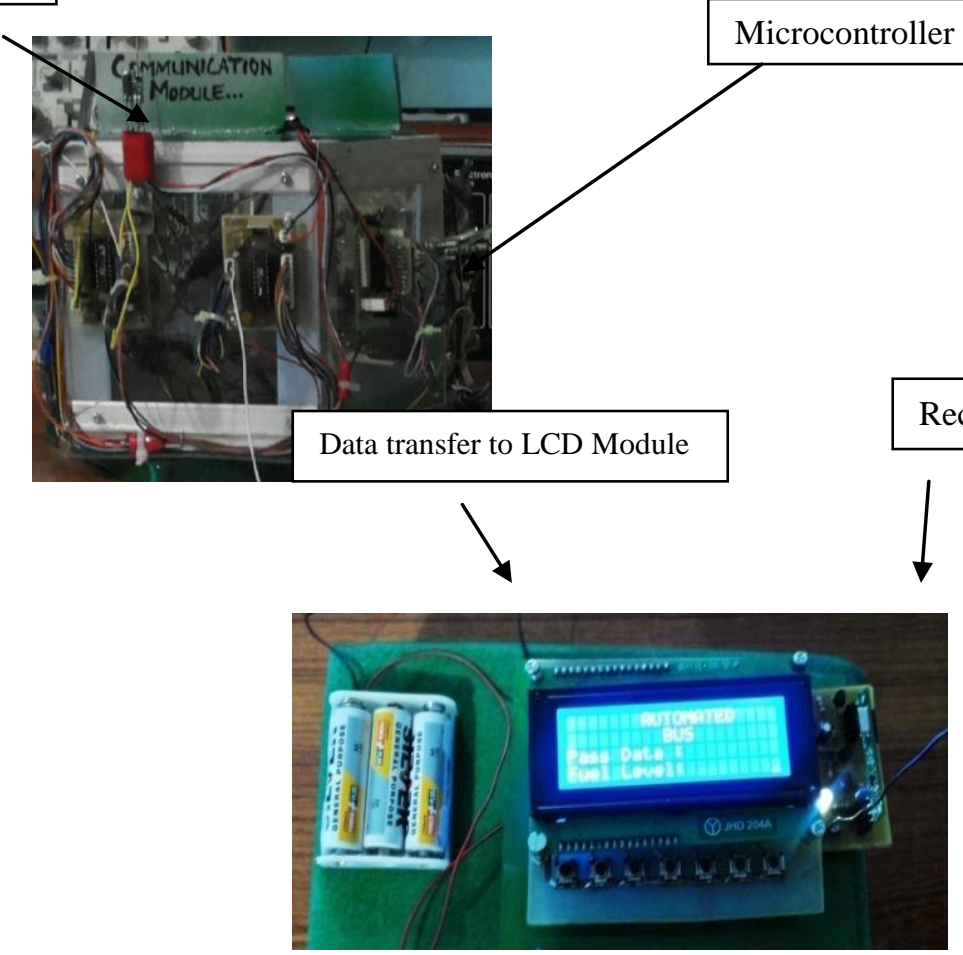

Figure 5-1 Implementation of Communication Module

In Software, we will be using proteus 8, assembly 8051, Keil C for 8051 for integration of Software and hardware.

\section{Business Potentials}

Our proposed system benefits both ways, the owner and the directorate of the company can earn more and employees will be benefited modernized world bus transport system is accompanied by advance technologies which includes bus card machine and ticket selling machine. Our project will be aimed at developing sensors and controllers based solution for fleet management and monitoring for commercial use. Our aim is to minimize the problems and mismanagement in transport management and handling it electronically

\section{Conclusion}

Five modules are made, each for a specific purpose and will be interlinked to each other. Communication Module is the main module, collecting data from every module and sending it wirelessly to the owner. And hence owner can keep a check on everything ensuring corruption-free environment.

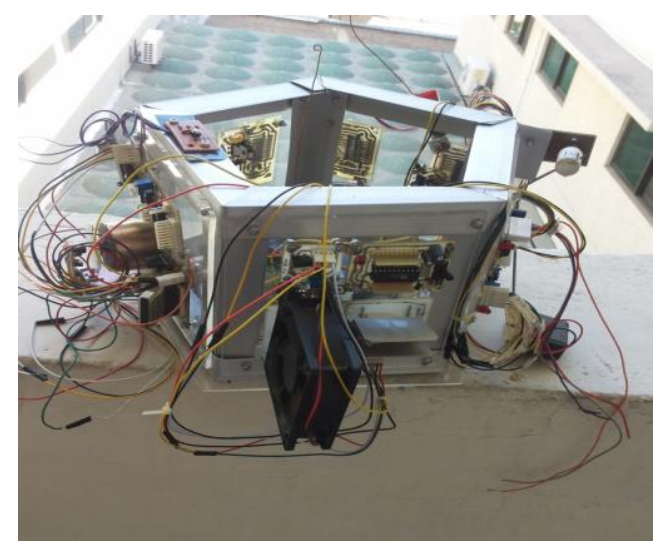

Figure 6: Implementation of All the modules on pentagon Structure 


\section{Acknowledgements}

First and foremost, we would like to thank Allah Almighty for blessing us with enthusiasm, courage, knowledge and energy to help us finish our final year project. We are thankful and would like to express our sincere gratitude for our supervisor Dr. Salman Afghani for his guidance, support and continuous encouragement in making this project possible. His guidance from initial to final level enabled us to achieve our objective of final year project.

Our sincere thanks to all the Lecturers who helped us in many ways, gave valuable advises and made our journey easy.

\section{References}

[1] MIN CHEN, GONZALEZ, S., LEUNG, V., QIAN ZHANG, MING LI. (2010) A 2G-RFID-based e-healthcare system. IEEE Wireless Communications ., 17: 37-43.

[2] Morgan, D.J. (2002) A Microscopic Simulation Laboratory for Advanced Public Transportation System Evaluation.

[3] Neubert, L., Esser, J., Schreckenberg, M (1999) A Cellular Automaton Traffic Flow Model for Online Simulation of Traffic.

[4] J. Smith and A. Ruffle, The Transport Asset Management System.

[5] C. Rizos, Public Transport Management System

[6] Ayala, K.J. The Microcontrollers. West Publishing Company, San Fransisco.

[7] CANGIALOSI, A., MONALY, J. E., YANG, S. C. (2007) Leveraging RFID in hospitals: patient life cycle and mobility perspectives. IEEE Communications Mag., 40:18-23.

[8] F. Wuhib, R. Stadler, and M. Spreitzer. A Gossip Protocol for Dynamic Resource Management in Large Cloud Environments

[9] HU J., LI G. (2006) Design of city-bus intelligent control system framework, In Proceedings of the 2006 IEEE International Conference on Mechatronics and Automation, Henan, China, p. 2307-2311.

\section{Authors}
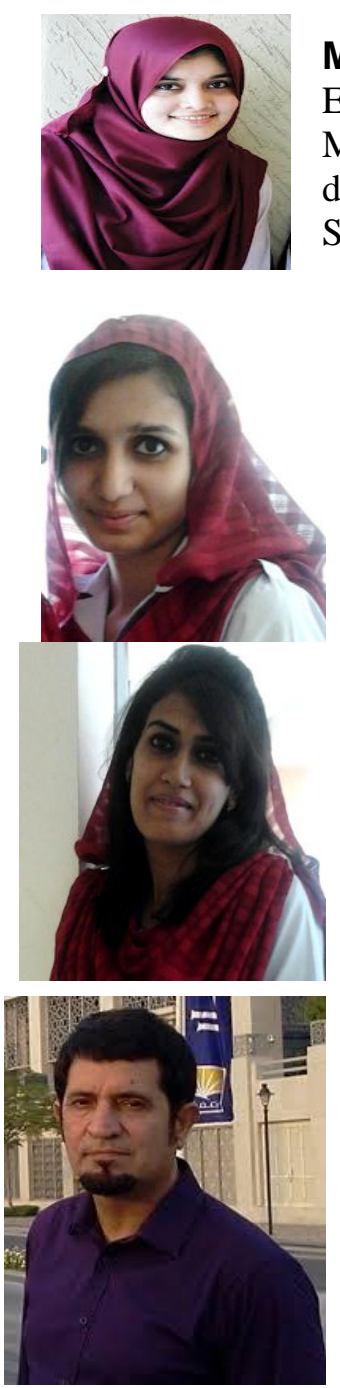

Mehwish Iqbal was born in 09/28/1990 in Pakistan. And she is an Electrical Engineer with specialization in Telecommunication from Army Public College of Management and Sciences (APCOMS), Rawalpindi Pakistan. Currently she is doing MS in Electrical Engineering (Telecommunication) from Military College Of Signals (MCS) - NUST, Rawalpindi Pakistan

Tayyaba Sabir was born in 10/27/1989 in Pakistan. And she is Electrical Engineer with specialization in Telecommunication from Army Public College of Management and Sciences (APCOMS), Rawalpindi Pakistan.

Shaista Noreen was born in 03/03/1992 in Pakistan. And she is Electrical Engineer with specialization in Telecommunication from Army Public College of Management and Sciences (APCOMS), Rawalpindi Pakistan.

Salman Afghani was born in 07/20/1958 in Pakistan and he is Professor, PhD, Advanced man machine systems, MPhil, Industrial automation, MS Mech Engg. He is working as HOD of R\&D Department of Engineering Sciences at Army Public College of Management and Sciences (APCOMS), Rawalpindi Pakistan. 